\title{
LA METAFÍSICA DE EMPÉDOCLES
}

La filosofía de Parménides, a cambio del rigor de su método y de la potencia de sus resultados, nos entrega una realidad totalmente inhospitalaria, en la que los hombres no pueden vivir y donde muy difícilmente podrían encontrar una razón de ser. Los mortales no son ciudadanos de ese mundo, sino de un mundo de sombras, irreal, producto del mero engaño de las palabras; único, sin embargo, en el que pueden desenvolver su existencia de cada día, en continuo trato con las cosas y sus semejantes, con sus alegrías, sus temores y sus esperanzas. Sólo la excesiva confianza depositada en el pensamiento racional y el consecuente uso único y exclusivo del voeiv podrían traer como consecuencia algo tan inhumano y despiadado. El hombre quedaba reducido así, por motivos meramente racionales y no ya religiosos, como en Píndaro, a la condición de "sueño de una sombra". 1 Parménides rechaza lo que de más concreto y humano hay en todo conocimiento: el testimonio de los sentidos, y con ello su campo de pensamiento se coloca por completo, como él mismo reconoce orgullosamente, "fuera del camino de los hombres". ${ }^{2}$ Tan es así que, en ocasiones, al leer su Poema nos asalta la duda de si nos está hablando un hombre verdadero o el pensamiento puro que no puede cometer equivocación alguna o errar el paso en su ruta hacia la Verdad. Pareja soberbia tenía que aparecer ante los ojos de los ciudadanos griegos de aquellos tiempos, como una temeridad literalmente des-piadada. La reacción contra esta hybris no tardaría en dejarse sentir. Con Empédocles, hombre piadoso si los hubo, podemos asistir a una vigorosa y patética repudiación de ese mundo tan frío e inhóspito que postulaba el eleatismo. Empédocles no tiene más pretensión que la de ser un mortal, un miembro de aquella raza contra la que se enderezaban todas las dưras invectivas del eleata; pero animado con el propósito de hacer valer todas sus posibilidades y medios de conocimiento, dentro de sus propios y muy humanos límites, ${ }^{3}$ a fin de aclarar las tinieblas que cubren la realidad. Nadie debe pretender rebasar tales límites ni debe aspirar a saber más de lo que el intelecto mortal puede alcanzar y ver. Basta escuchar las palabras con que se inicia su poema Sobre la Naturaleza, para percibir este nuevo sentido que con Empédocles cobra la meditación filosófica. ${ }^{4}$ El pensador debe percatarse ante todo de que es un mortal agobiado de flaquezas y

1 Píndaro, Pyth., 8, 96. Acerca del sentido exacto de esta cuestión en Píndaro y de sus conexiones con el pensamiento de Parménides, véase $H$. Fränkel, Dichtung und Philosophie des frühen Griechentums, American Philological Association, New York, 1951; págs. 603 y 639, n. 16.

2 Parm., B, 1, 27.

3 Acerca de las conexiones entre fe religiosa y limitación del saber humano en Empédocles, véase E. Bignone, Empedocle, Fratelli Bocca, Torino, 1916; pág. 134, n. 1.

4 Emp., B, 2, 1-2. 
debilidades, y no creerse entronizado sin más en las cimas de la sabiduría. ${ }^{5}$ Que en estas frases haya, tal como se ha creído, una directa alusión a Parménides, es lo más probable; ${ }^{6}$ pero, en todo caso, no menos patente queda el hecho de que en ellas se establece una muy distinta visión del papel propio del filósofo, en comparación con el que le asignara el eleata. Sólo la humildad ha de permitir el acceso a la verdad. Una humildad que se revela tanto en la acatación de la condición humana, como en la aceptación de todos los medios de aprehensión ( $\pi \alpha \lambda \alpha$ á $\alpha$ ) de que dispone el hombre. ${ }^{7}$ Todos pueden aportar un conocimiento, todos son vías para acceder a él, sean los sentidos o el pensamiento. ${ }^{8}$ Pues, en Empédocles no encontramos algo parecido a la repudiación eleática de los sentidos. ${ }^{9}$ Sólo que menester es darle a cada uno de estos diferentes medios de aprehensión su valor correspondiente y tomarlo dentro de sus propios límites. ${ }^{10}$ Empédocles nos invita a prestar fe a los sentidos; ${ }^{11}$ pero sin olvidar que el pensamiento es lo único que permite interpretar exactamente lo que ellos testifican. ${ }^{12}$ Lo equivocado sería tomar la parte por el todo. $\mathrm{Y}$ justo quien aprende a usar todos sus medios de aprehensión no conoce ya únicamente una pequeña parte de su propia vida ${ }^{13}$ sino todas

5 Emp., B, 2, 2 y B, 3, 8.

6 Véase Bignone, op. cit., págs. 143-144 y 391. Cf. Jaeger, La teología de los primeros filósofos griegos, Fondo de Cultura Económica, México, 1952; pág. 135.

7 Emp., B, 3, 9 y B, 2, 1.

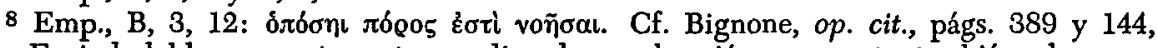
n. 1. Es indudable que entre estos medios de aprehensión se cuenta también el pensamiento; pues el fenómeno de "ver" no sólo se logra por medio de los sentidos, como haría pensar el fragmento 3,9-11, sino también con el pensamiento, según se advierte por el

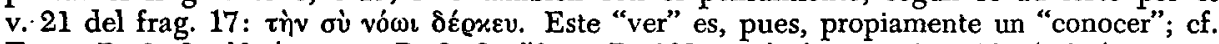

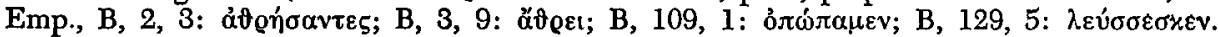
Cf. Karl Joël, Geschichte der antiken Philosophie, J. C. B. Mohr, Tübingen, 1921; I, pág. 526.

9 El valor que Empédocles concede a los sentidos explica el porqué de los testimonios de Aristóteles y Teofrasto relativos a la identificación que creen encontrar en él entre el pensar ( Teofr., de sensu, 10 (D. 501). Obsérvese, sin embargo, que Teofrasto admite tal identificación con una cierta reserva, pues nos dice que, para Empédocles, el pensar y el percibir

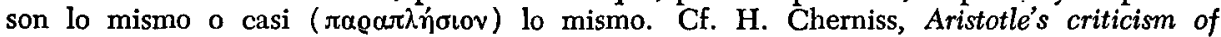
presocratic philosophy, The John Hopkins Press, Baltimore, 1935; pág. 81 y J. Zafiropulo, Empédocle d'Agrigente, Les Belles Lettres, Paris, 1953; págs. 159-164.

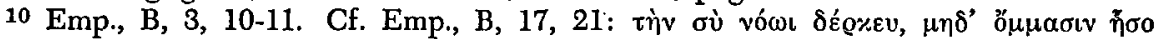
$\tau \varepsilon 0 \eta \eta \dot{s}$, donde se hace evidente el deslinde entre dos distintas formas de conocimiento. Que el conocimiento que puede dar a su poseedor la facultad de tener una vista de la totalidad del universo y del conjunto de las cosas, esté íntimamente ligado a la sangre, mezcla en proporción igual de las cuatro raíces (Emp., B, 98), parece indicarlo Emp., B, 105. Acerca de esta cuestión, véase Aram M. Frenkian, Etudes de Philosophie présocratique, II, J. Vrin, Paris, 1937; págs. 50-52.

11 Emp., B, 3, 12-13.

12 Véase Bignone, op. cit., pág. 657, n. 2.

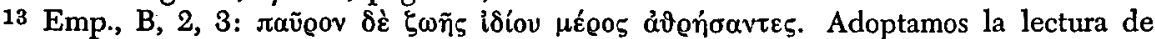

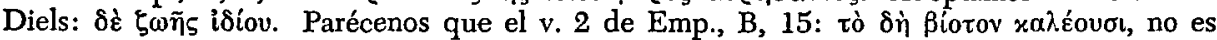
una razón decisiva para preferir la lección de Escaligero ( $\xi \omega \tilde{n}_{5}$ ảßíov) que han adoptado 
las cosas que hay en diez o en veinte vidas. ${ }^{14}$ Claro está, por otra parte, que tal conocimiento no puede explicarlo todo $;^{15}$ pero es lo único que permitirá al hombre rebasar sus debilidades, lo único que le facilitará los medios de desenvolver su existencia, ofreciéndole el dominio de la Naturaleza. ${ }^{10}$

Las consecuencias de tal modo de proceder llevan, como ya puede pensarse, a resultados bien distintos de los que nos entrega la teoría eleática del conocimiento. La realidad con Empédocles se humaniza. Su xóopos es un mundo donde los hombres vuelven a sentirse como en un hogar; puesto que, por una parte, todas las diferencias cualitativas vuelven a ser admitidas en él y, por otra, al revés de lo que sucedia en Parménides, el mismo hecho del conocimiento no nos contrapone a ese mundo, sino antes bien nos hace comulgar más estrechamente con él. El macro y el microcosmo ${ }^{17}$ encuentran su lazo de unión en esa ófoเoлáveı $\alpha$ que es central en la gnoseología de Empédocles. ${ }^{18} \mathrm{Si}$ podemos conocer el mundo es porque somos parte de él, porque los mismos componentes entran en él y en nosotros. La oposición entre verdad e ignorancia se resuelve ahora de un modo más simple. La verdad consistirá en la semejanza que haya entre el componente conocido y el cognoscente, y la ignorancia en su diferencia. ${ }^{19}$

Con todo, a pesar de las divergencias que pueden encontrarse entre Parménides y Empédocles, este último queda unido al primero en ciertas de sus concepciones básicas. Empédocles, al igual que el eleata, rechazará toda posibilidad de una generación dada a partir del no ente, tanto como de una destrucción que conduzca a él. Pero ya de antemano podemos suponer que esta postura arrastra muchos elementos nuevos que hubiera sido imposible encontrar en la doctrina del eleata. El compromiso entre los sentidos y el eleatismo que, como nos decía Burnet, ${ }^{20}$ representa la filosofía de Empédocles, ofrece una clara razón del porqué de ello. Las semejanzas entre estos pensadores se harán evidentes por poco que nos detengamos en el fragmento nú-

entre otros Burnet y Bignone, así como no lo es la expresión similar que Bignone, op. cit., pág. 389, encuentra en Gorgias, $B, 11$ a 21: Bío $\delta \dot{\varepsilon}$ oủ Bıtotós.

14 Emp., B, 129, 5-6. De aceptarse la lección de Diels de Emp., B, 2, 3 (véase n. 13), se establecería en estos fragmentos una contraposición entre los frutos que produce el conocimiento y la mísera situación en que se ve quien ni siquiera ha alcanzado lo que la meditación y el conocimiento humanos pủeden brindar (cf. Emp., B, 2, 8-9).

15 Emp., B, 2, 8-9. Cf. Bignone, op. cit., pág. 139 y Stenzel, Metaphysik des Altertums, R. Oldenbourg, München und Berlin, 1931; pág. 70, 26-28.

16 Emp., B, 111. Sobre esto, véase Wilhelm Nestle, Vom Mythos zum Logos, Alfred Kröner Verlag, Stuttgart, 1940; pág. 114.

17 Este concepto lo encontramos expresado por primera vez en Demócrito, B, 34; pero en forma implícita está ya en Empédocles. Karl Joël, op. cit., pág. 553, refiriéndose a esto mismo, nos decía: "das Ineinanderleben der Natur mit dem Menschen, die Einheit des Makrokosmos und Mikrokosmos ist geradezu der Sinn seiner Lehre".

18 Emp., B, 107 y B, 109. Véase Bignone, op. cit., pág. 146. Cf. Stenzel, op. cit., pág. $71,18-19$.

19 Teofr., de sensu, 10 (D. 501 ); Arist., Metaph., B, 4, 1000b 5.

20 Burnet, Early Greek Philosophy, Adam and Charles Black, London, 1952; pág. 227. 
mero doce de Empédocles. En efecto, ahí se nos afirma muy nítidamente que

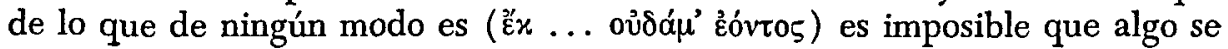
genere, al igual que es imposible e impensable que lo que es pueda desaparecer. ${ }^{21}$ Pero, no obstante, Empédocles habrá de aceptar una "generación" y una "destrucción", sólo que tomándolas en un sentido muy distinto del anterior. En un sentido en que no impliquen en lo más mínimo el no ente absoluto como condición de posibilidad.

Es tener pensamientos de muy corto alcance -nos dice Empédocles- el suponer que lo que no es antes se ha generado -pasando de lo que de ningún modo es a lo que es- o que las cosas mueren y se destruyen totalmente. ${ }^{22}$ En este punto, Empédocles sigue en lo fundamental el camino que estableciera la doctrina eleática, aunque también se apunta aquí un nuevo concepto que no hubiera tenido acogida en ella y que nos permitirá aclarar el nuevo aspecto que van a cobrar ahora la generación y la destrucción. Pues, en efecto, para Empédocles, las cosas pueden no haber sido, tal como lo revela este fragmento, pero ello no significa que para "generarse", o llegar a ser lo que son, tengan que haber surgido de lo que no es. Igualmente pueden "destruirse", pero ello tampoco quiere decir que tengan que destruirse totalmente, o lo que es igual, que tengan que desaparecer en la nada. Que algo no haya sido viene a significar aquí simplemente que ese algo fue o existió antes tanto como ahora, sólo que antes se presentaba de un modo muy distinto a como ahora se presenta. Esto quiere decir que de algo previamente existente surge o se "genera" algo nuevo, algo que antes no se veía. Y lo mismo podría decirse, sólo que a la inversa, de la "destrucción".

El mecanismo real de tales procesos tiene, para Empédocles, una índole muy simple y se enlaza íntimamente con sus concepciones acerca de la constitución de la realidad. Los integrantes de ésta son, por un lado, las raíces -Agua, Tierra, Fuego y Aire- y, por otro, el Amor y el Odio. ${ }^{23}$ Todos ellos son inengendrados e imperecederos ${ }^{24} \mathrm{y}$ cada uno conserva siempre (aićv) su

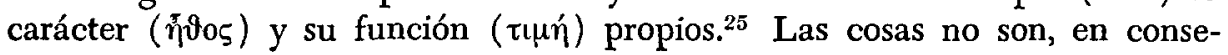

21 Emp., B, 12, 1-2. Véase más adelante n. 45.

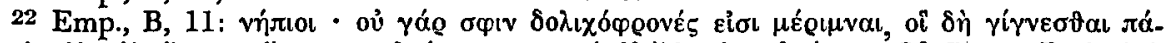

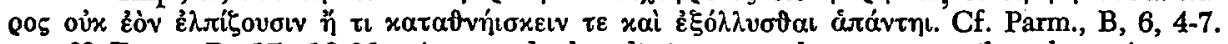

23 Emp., B, 17, 18-20. Acerca de los distintos nombres que reciben las raíces en Empédocles, véase $\mathrm{O}$. Gilbert, Die meteorologischen Theorien des griechischen Altertums, B. G. Teubner, Leipzig, 1907; págs. 107-108 y 110-111.

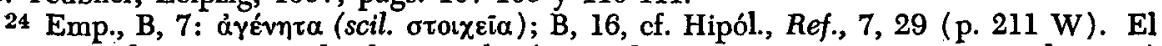
curioso texto de $\mathrm{B}, 17,27$, donde, en relación a todos estos componentes, se nos dice: xai

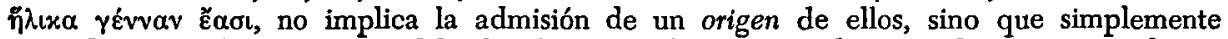
trata de poner de manifiesto el hecho de que cada uno de tales ingredientes es igualmente primario e inderivable de otro, a la inversa de lo que sucede con la filosofía jónica que hace derivar toda la multiforme realidad de un solo "elemento". Véase Arist., de caelo, 305a 32-305b 6. Arist., de gen. et corr., A, 1, 315a 4-5; B, 1, 329b 1; B, 6, 333a 16-20; B, 6, 333b 9-11; Meteor., A, 3,340a 13-15. Cf. Bignone, op. cit., pág. 407 y 0. Gilbert, op. cit., págs. 105-106.

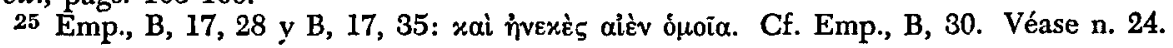


cuencia, más que el resultado de la unión de tales raíces, ${ }^{26}$ de acuerdo con una determinada ratio que fija la proporción en que las raíces entran en esa unión y que es peculiar para cada cosa distinta. ${ }^{27}$ Con todo, semejante unión no es estable $y$, justamente, es esta inestabilidad lo que constituye la condición de posibilidad de que las cosas sean, en un cierto sentido, mortales

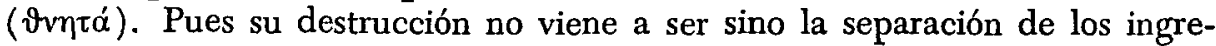
dientes que las componen. $E$ inversamente su generación equivale a la mezcla proporcional de ellos. ${ }^{28}$ Semejante explicación vale para todos los com-

26 Emp., B, 21, 9-12. Cf. Emp., B, 22, 1: ăg

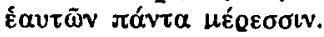

27 Emp., B, 23. En este fragmento se expone la cuestión con una gran claridad a partir de la comparación entre la formación de las cosas mortales y la mezcla de colores que, en las proporciones debidas, realizan los pintores. Un ejemplo de tal ratio lo tenemos en Emp., B, 96, donde se nos muestra la proporción en que entran las raíces en la formación del hueso. Cf. Emp., B, 98, en relación a la sangre y otras formas de la carne. La

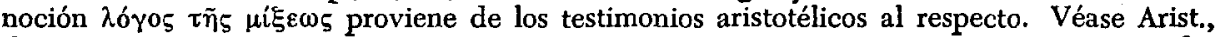
de part. anim., A, 1, 642a 17-24; de anima, A, 4, 408a 13-20 y A, 5, 410a 1-6; Metaph., A, 10, 993a 15-22; de gen. et corr., B, 6, 333b 9-11. Pseudo-Arist., de spiritu, 9, 485b

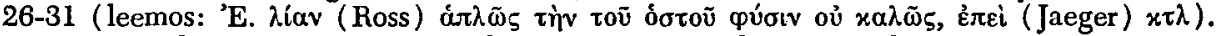
Las dificultades surgen cuando se plantea la cuestión de si todas las cosas están compuestas de las cuatro raíces o si también pueden estarlo por un menor número. El fragmento 96 de Empédocles y el testimonio de Aecio, V, 22, 1, apoyarían la segunda alternativa; pues, en efecto, en ninguno de estos dos textos se nos dice que los huesos estén formados también por Aire, sino tan sólo por dos partes de Agua (N ñotıs = Agua, apud Simpl., de anima, 68, 10 y Estobeo, ecl. phys., I, 10,11b W.), dos de Tierra ( $\chi \vartheta \hat{\omega} v$ ) y cuatro

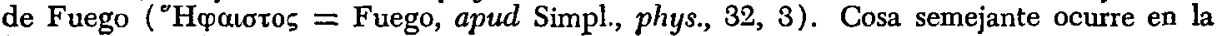
formación de los nervios (véase Aecio, V, 22, 1). Sin embargo, Teofrasto y Simplicio se deciden por la primera alternativa. Véase Teofr., de sensu, 23 y Simpl., de anima 68, 5-10. Según ellos, por lo tanto, en la formación del hueso entrarían todas las raíces: una parte de Agua, dos de Tierra, cuatro de Fuego y una de Aire, tal como nos lo dice Simplicio. Estas noticias son evidentemente erróneas. Prueba de ello es que en el fragmento que Simplicio comenta se nos dice muy claramente que los huesos tienen dos partes de Agua y no una. Aristóteles no aclara suficientemente la cuestión por lo que toca a la composición de los huesos; pero deja entrever que las cuatro raíces no entran todas necesariamente en la for-

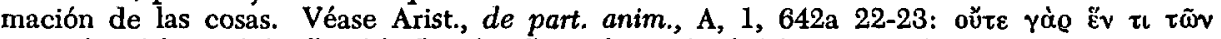

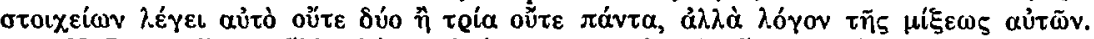

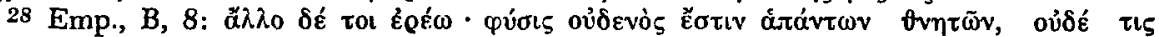

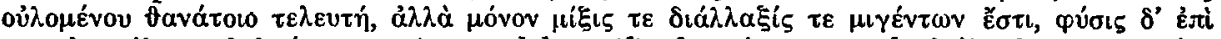

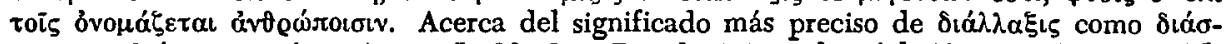

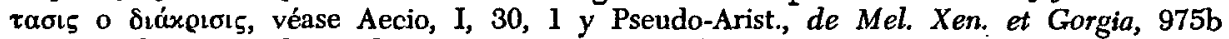
13-14. Plutarco, adv. Colot., 10, $1112 \mathrm{~A}$, parafrasea este texto usando la oposición

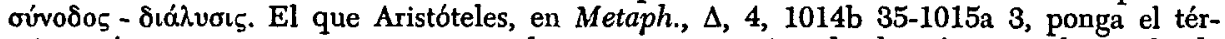

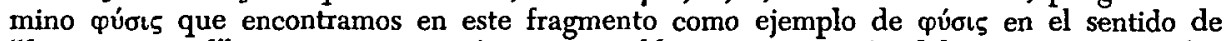
"forma esencial", no constituye más que una libre interpretación del pensamiento auténtico de Empédocles, y sería erróneo atribuirle más valor que éste. El hecho se explica si

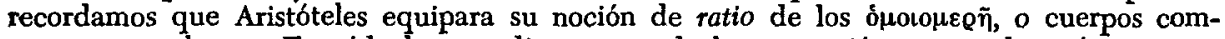
puestos, con lo que Empédocles nos dice acerca de la proporción en que las raíces entran

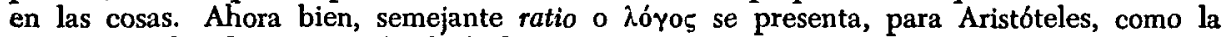

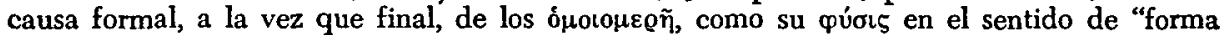
esencial" (Arist., de gen. et corr., B, 6, 333b 16-17 y 19; de anima, A, 4, 408a 15-16; de gen. anim., A, 1, 715a 2-6; Metaph., A, 10, 993a 18; $\Delta, 4,1015$ a 10-11. Véase Bonitz, Index Aristotelicus, ed. Acad. Regia Boruss, Reimer, Berolini, 1870; pág. 434b 13-44). Esto mismo es justamente lo que Aristóteles cree encontrar de modo implícito por primera 
puestos; ya sea que pertenezcan éstos al orden cósmico o al biológico; ${ }^{29}$ puesto que todo lo mezclado presupone necesariamente una "generación" y está irremisiblemente destinado a la "destrucción". 30

Según Empédocles, por lo tanto, lo que se oculta en el fondo de palabras tales como nacimiento, generación, destrucción o muerte, no es sino una mezcla o separación. Cabría esperar, en vista de ello, que dichas expresiones

vez en esa "proporcionalidad" de las raíces que postulaba Empédocles (cf. Arist., phys., B, 2, 194a 20-21), y tal es la razón de que en ocasiones la exponga como si se tratara de su misma noción de ratio (Arist., de part. anim., A, 1, 642a 17-24; de anima, A, 4, 408a 18-20.) Pero ya desde un punto de vista crítico, Ariștóteles le reprochará a este filósofo el que no se haya percatado de la verdadera causa que con ello ponía en juego, puesto que las raíces no son sino causa material, así como el Amor y el Odio son a lo sumo causa de la mezcla y separación, esto es, causa eficiente y nada más (Arist., de gen. et corr., B, 6, 333b 11-13; Metaph., A, 10, 993a 20-24.) Conformarse pues, con hablar únicamente, en relación a la composición de las cosas, de mezcla y separación, equivale sin más a dejar todo en manos de la fortuna ( túxn) (Arist., de gen. et corr., B, 6, 333b 14-16. En este sitio, como ya lo hacía notar Joachim, Ar. hace una parodia irónica del v. 4 del frag. 8 de Empédocles, cambiándole totalmente el sentido), y esto no sólo porque todo lo que acaece según la fortuna tiene una causa indeterminada (Arist., Rhet., A, 10, 1069a 31)

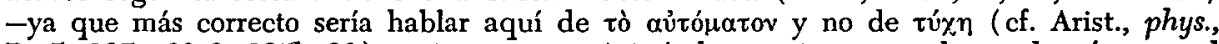
B, 5, 197a 32-6, 197b 22)-, sino porque Aristóteles tropieza con el uso de túxn en el mismo Empédocles (Arist., phys., B, 4, 196a 16-24; de gen. et. corr., B, 6, 334a 2-3; Emp.,

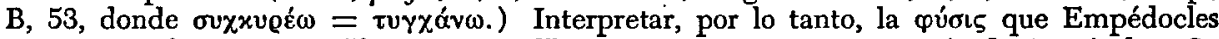
niega en su frag. 8 como "forma esencial", no viene a ser sino una ironía de Aristóteles. Su manera arbitraria de citarlo basta para confirmar esto; pués, si Aristóteles no hubiera

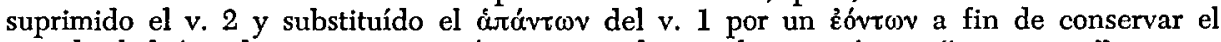
sentido, habría sido patente que púors no puede significar aquí sino "nacimiento", en vir-

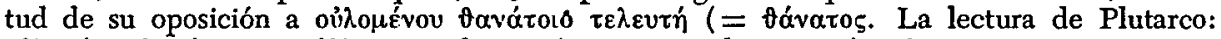

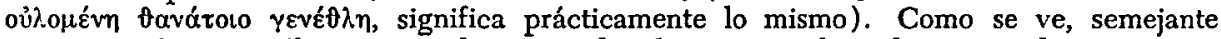
interpretación aristotélica no ayuda en modo alguno a probar el parecer de Lovejoy y Burnet acerca de que púøı signifique en Empédocles "substancia" o naturaleza permanente. Según estos autores, Empédocles habría querido decir simplemente que las cosas no tienen una naturaleza permanente propia y que por ello su muerte no tiene fin: mueren $\mathrm{y}$ mueren interminablemente (véase J. Burnet, Greek philosophy, Thales to Plato, Macmillan, London, 1953; págs. 73-74). Sin embargo, el testimonio de Plutarco, adv. Cólot.,

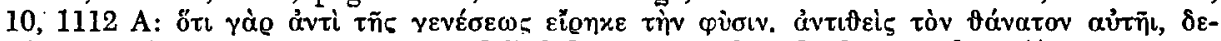

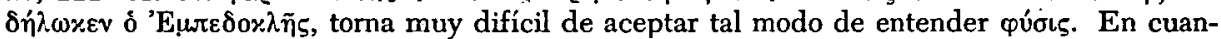

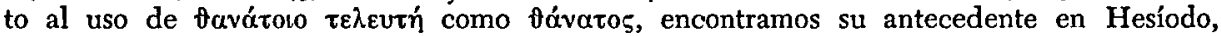
Scut. Herc.; 357. Pero, por otra parte, de aceptar el punto de vista de Burnet, se produciría un grave desacuerdo entre Emp., B, 11 y el último verso de este fragmento. No parece, pues, ofrecer mayores dudas el que pv́oı deba tomarse aquí, al igual que en Emp., B, 63 (véase Kranz, Wortindex, pág. 464a 12-15), como el substantivum actionis de qúzơdal, como "Entstehung" o nacimiento. Por su parte, F. Heinimann, Nomos und Physis, Verlag Friedrich Reinhardt, Basel, 1945; págs. 90-91, ha demostrado muy convincentemente que púors tiene el mismo significado en el fragmento 10 de Parménides, y ha destacado la estrecha conexión no sólo ideológica, sino terminológica, que guarda el frag. 8 de Empédocles con Parm., B, 19, donde encontramos la oposición qũval - $\varepsilon \varepsilon \lambda \varepsilon v \tau \tilde{\alpha} v$.

29 Cf. Emp., B, 9, 1-4; B, 21, 9-14; B, 38. En el v. 1 de este último fragmento

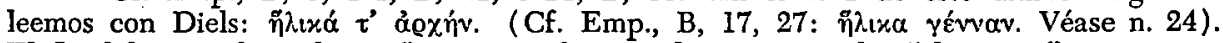
El $\tilde{\omega} v$ del v. 2, al igual que $\eta^{\prime} \lambda \iota \alpha$, se refiere evidentemente a los "elementos".

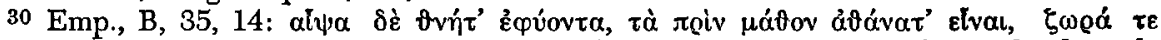

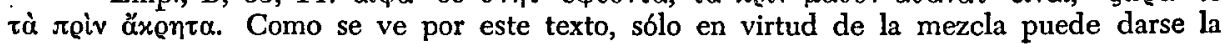
“mortalidad". Cf. J. Burnet, Early Greek Philosophy, ed. cit., pág. 212, n. 1. 
que no dan cuenta fiel de los verdaderos procesos de la realidad fueran evitadas cuidadosamente en todos aquellos sitios donde no se las trata meramente qua expresiones, y substituídas por las adecuadas. Pero ello no es así, sino todo lo contrario. Empédocles muestra una marcada preferencia por su uso, no obstante que reconoce y subraya la incorrección que implican. La causa de este proceder quedará aclarada si reparamos suficientemente en el sentido último del siguiente verso:

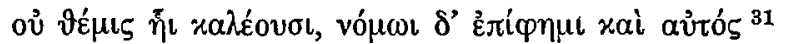

El modo incorrecto de expresión a que alude el primer hemistiquio es justa. mente, como se desprende de lo que lo antecede, el hecho de calificar como generación o destrucción lo que no es sino mezcla o separación. Hasta aquí no hay dificultad alguna. Sin embargo, el segundo plantea toda una serie de cuestiones que las más de las veces han sido pasadas por alto, sin atender a su singular importancia. En primer término conviene destacar que el verbo

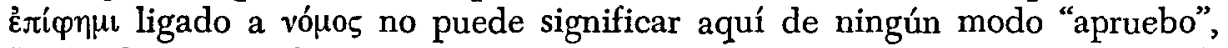
"estoy de acuerdo".32 El que en una glosa de Hesiquio encontremos la igual-

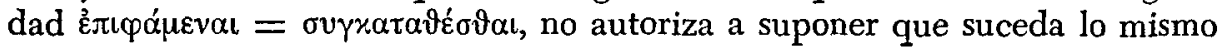
en Empédocles. Claro está que en esta frase se señala una relación entre la actitud de Empédocles y el vónos; pero no una relación de aprobación o aquiescencia. ${ }^{33}$ La cuestión se aclara si nos percatamos de lo que mienta aquí nomos. Es indudable, tal como lo ha demostrado Heinimann, que en este tex-

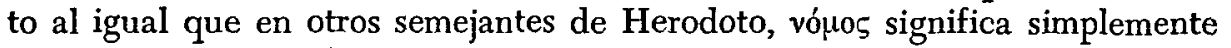
"uso del lenguaje" (Sprachgebrauch), ${ }^{34}$ y si Empédocles para expresarse se atiene al nomos, ello no quiere decir sino que se atiene al uso del lenguaje corriente. La razón de ello es fácil de entrever: se utiliza tal lenguaje a causa de su universal comprensibilidad, de su mayor ámbito de comunicabilidad e inteligibilidad. Basta esto para caer en la cuenta de cuán errada es la suposi-

31 Emp., B, 9, 5. La lectura Wilamowitz de la primera frase de este verso tiene

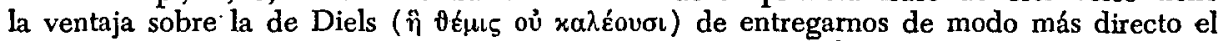

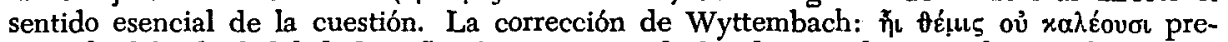
senta la dificultad del dudoso 触 télus. Acerca de las diversas lecturas de esta frase, véase el aparato crítico del Diels-Kranz y Mullach, Fragmenta Philosophorum Graecorum, F. Didot, Paris, 1860; I, pág. 34, n. al v. 111.

32 Tal como lo toma; por ejemplo, en relación al mismo texto de Empédocles, el Liddell-Scott. Siguiendo el mismo parecer, Covotti, I presocratici, Rondinella Alfredo, Napoli, 1934; pág. 164, traduce el v. 5 del frag. 9 de Empédocles en la siguiente forma: "Senza diritto alcuno: sebbene ubbidisca io stesso a tale usanza."

33 Así parece haberlo entendido en un sitio Plutarco. Véase Plut., adv. Colot., 11, $1112 \mathrm{~F}$ : vع 34 Felix Heinimann, op. cit., págs. 82-83 y 85. Karl Reinhardt, Parmenides und die Geschichte der griechischen Philosophie, Friedrich Cohen, Bonn, 1916; pág. 87, nos hablaba de un "erkenntnistheoretischer Ursprung" del concepto vónos en Herodoto; pero, como muy bien lo hace notar Heinimann, en Herodoto, IV, 39, "no se encuentra huella alguna de un origen gnoseológico" de tal concepto. 
ción de que vónos tenga que significar en el verso citado "opinión falsa"; 35 puesto que sería absurdo pensar que Empédocles se atuviera a ella. ${ }^{36}$ Es obvio, por otra parte, que atenerse al uso del lenguaje corriente, no implica el aprobarlo, el admitir su corrección o adecuación con la realidad, sino que equivale simplemente a servirse de él como medio para lograr una mayor difusión y mejor comprensión de las ideas expuestas. ${ }^{37}$ Se trata, en suma, de utilizar una serie de palabras para facilitar el apropiamiento de la doctrina; pero sin tomar para nada en cuenta -ni mucho menos aprobar- la "opinión falsa", como sería el caso si así se hubiera que entender vón05.

Esta interpretación concordante en todo con el espíritu de la teoría y los textos de Empédocles, ${ }^{38}$ parece ser confirmada por un texto del tratado hipo-

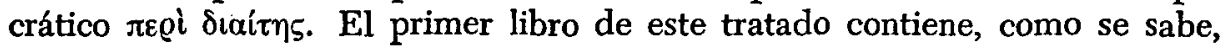
hasta el capítulo 24, una mezcla de las doctrinas de Anaxágoras, Empédocles

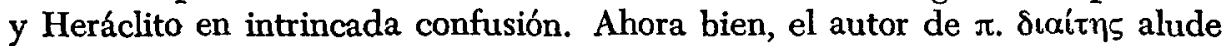
en un sitio manifiestamente a los versos de Empédocles (B, 9, 1-4) que anteceden al que nos ocupa ${ }^{39}$ y unas líneas más adelante escribe: $\mathbb{0}^{8} \tau \iota \delta^{\prime} \stackrel{\alpha}{\alpha} v$

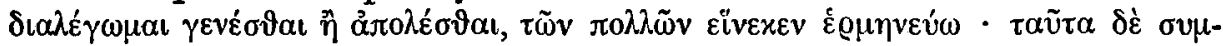

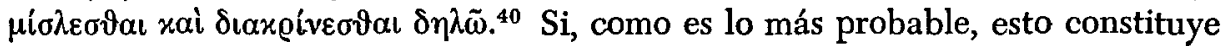

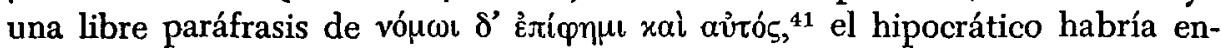
tendido dicha frase de Empédocles como significando "me expreso atendiendo al uso del lenguaje habitual por mor de la universal comprensión de lo

35 Véase, por ejemplo, Karl Joël, op. cit., pág. 544, n. 3. Reinhardt, op. cit., p. 86, ha sostenido que "Empedokles verwendet das Wort vónac im demselben schulmässigen Sinne wie Leukipp", refiriéndose al testimonio de Aecio, IV, 9, 8, acerca de Leucipo; interpretación ésta que a nuestro parecer no se sostiene si se examinan los textos más a fon-

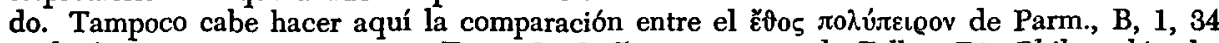
y el vó $0_{5}$ que encontramos en Emp., B, 9, 5, como pretende Zeller, Die Philosophie der Griechen, O. R. Reisland, Leipzig, 6. Aufl., 1920; I, 2, pág. 1027, n. 2.

38 Cf. Heinimann, op. cit., pág. 85.

37 Heinimann, op. cit., pág. 85, nos dice refiriéndose a vóuos: "Dessen Kennzeichen ist die allgemeine Guiltigkeit, nicht die Unrichtigkeit, und sie ist es, die sogar Empedokles zwingt, sich seiner zu bedienen, wenn er fïr alle verständlich reden will."

38 Sobre vouí̧દơđal en Emp., B, 17, 22, véase Heinimann, op. cit., pág. 85.

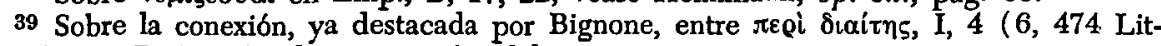
tré) y Emp., B, 9, 1-4 volveremos más adelante.

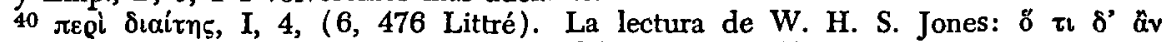

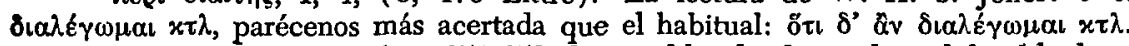

41 Bignone, op. cit., págs. 651-658, ha establecido de modo indubitable la estrecha

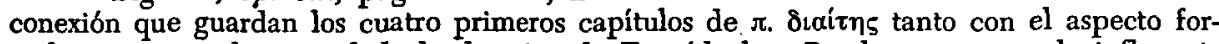
mal, como con el material de la doctrina de Empédocles. Por lo que toca a la influencia que el cap. 4 haya podido sufrir de Anaxágoras, puede decirse que éstas son indudables

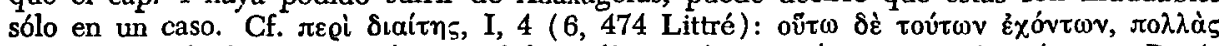

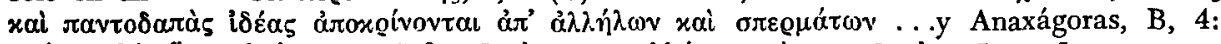

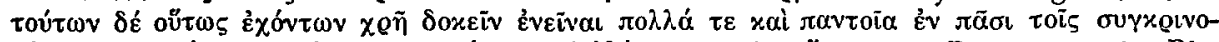

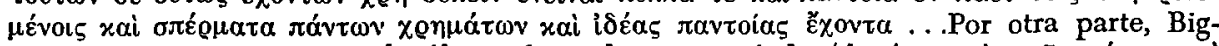

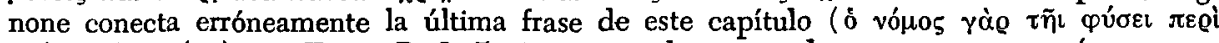

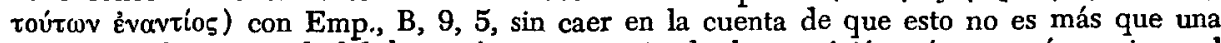
interpretación personal del hipocrático, a partir de la oposición vóuos - púoıs ajena al pensamiento de Empédocles. 
que pienso, aunque sin concederle a éste más valor que el de un artificio de exposición".

Lo equivocado sería tomar precisamente tal lenguaje al pie de la letra; porque ello sólo una falsa suposición lo haría posible.42 Oscuridad e imprecisión son, para Empédocles, las características del $x \alpha \lambda \varepsilon i v$, de toda expresión que no se ajuste a la verdad de su doctrina $y$, por ende, que no sea adecuada a la realidad. ${ }^{43}$ Pues, en efecto, de no ser metafóricamente, como él las emplea, todas esas expresiones dejan en tinieblas los verdaderos procesos cósmicos. $\mathrm{Y}$, lo que es más grave y de mayor importancia para nosotros, posibilitan la intromisión de un no ente no dilucidado en el seno de la realidad. Parménides hubo de ver ya que todo cambio presuponía lo que no es y por eso hubo de desterrarlo. El precio era muy alto; pero era el único que garantizaba la completa exclusión de todo no ente. Una confirmación bien luminosa de esto la tenemos en Empédocles. Este filósofo, al aceptar la incesante transformación debida a las mezclas y separaciones de los elementos, se verá constreñido a aceptar paradójicamente un cierto tipo de "no ente" muy especial.

En términos generales Empédocles reconoce, al igual que el eleata, la total alteridad de lo que es ( $\tau$ c̀ ćóv) frente a lo que no es. Hemos visto ya que es imposible e insostenible el que haya un paso de lo que no es en modo absoluto a lo que es y viceversa. ${ }^{44}$ Tal imposibilidad, podemos sospecharlo, alude tanto a una imposibilidad de hecho, como a la imposibilidad de pensar y sostener que ello es así. ${ }^{5}$ Pero, por otra parte, dentro del sistema empedocliano es lícito afirmar que hay entes que son y entes que no son, porque ya fueron o serán. ${ }^{46}$ Es claro, con todo, que lo que antes no es, ${ }^{47}$ tanto como lo que

42 Emp., B, 11, 2.

43 Cf. Emp., B, 9, 5; B, 15, 2 y B, 17, 24. El verbo xaגeiv es usado exclusivamente por Empédocles, para designar en general el lenguaje basado en una mala estimación de la realidad. Cf. Heinimann, op. cit., pág. 49, n. 15.

44 Véase Emp., B, 12.

45 La interpretación que hace Bignone, op. cit., págs. 398 y 400 , del v. 2 de Emp.,

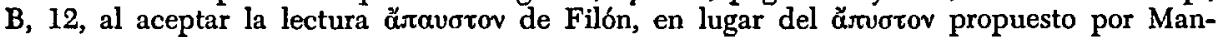

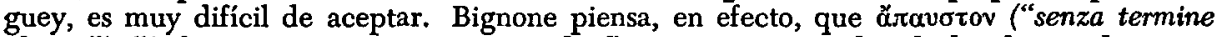
alcuno") "è legitimo $e$ giustamente rende largomentazione che il dissolversi dei corpi debba avere un termine, del resto si giungerebbe all annullamento della sostanza, che in tal caso non esisterebbe oramai più". El término de que aquí se nos habla lo constituirían las cuatro raíces; pero ¿̇no es de pensar acaso que también la nada constituya el "término"

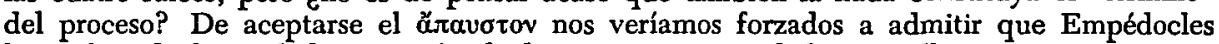
ha rechazado la total desaparición de lo que es en virtud de que ella presupone un proceso al infinito y no en virtud de que este proceso tenga, como Bignone dice, que conducir a la nada, en el caso de no terminar en la separación de las cuatro raíces. Pero la verdadera consecuencia que se desprende del ö́ravorov no está reñida en modo alguno con el resto de la doctrina de este filósofo, y sería absurdo verla como una prueba en contra de tal "desaparición total". Es muy dudoso, por otra parte, que $\dot{\varepsilon} \xi \alpha r o ́ \hat{\imath} \lambda u \mu \mu$ tenga aquí el sentido de "disolver" y no más bien el de "desaparecer". Que aquí haya que leer örvvorov, dándole el sentido de una imposibilidad por motivos racionales, lo hace pensar el corres-

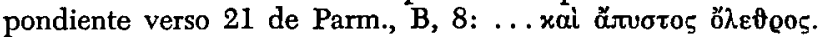

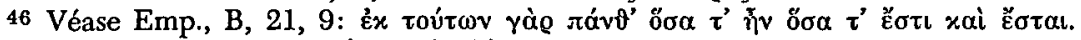

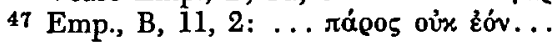


será después, existe, sólo que bajo un aspecto distinto. Ello significa que las transformaciones a que se ve sujeta la realidad son la condición de posibilidad de que se pueda hablar de algo que no es, puesto que decir que algo no es equivale a decir que es de otra manera que como fue o será. Ello significa también que sólo el Amor y el Odio caen fuera de semejante posibilidad, puesto que como no son elementos constitutivos en ninguna mezcla, no pueden haber sufrido ni estar por sufrir transformación alguna. Las raíces, en cambio, a pesar de ser siempre iguales, ${ }^{48}$ llegan a ser, debido a su mezcla y separación, una vez esto y otra vez aquello, ${ }^{40}$ es decir, se diferencian cambiando de aspecto una y otra vez, ya que en las mezclas no aparecen en cuanto tales. ${ }^{50}$ De acuerdo con lo anterior, es obvio que no puede decirse que el Amor y el Odio no son como han sido o como serán, sino que, por el contra-

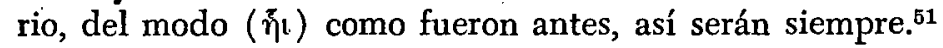

Pero los diferentes tipos de entes "mortales", que resultan en virtud de la mezcla de raíces, ${ }^{52}$ son de un modo y no son de otro. Antes de verificarse la proporcional mezcla que los constituye o después de disolverse no son nada de lo que ahora son. ${ }^{53} \mathrm{Y}$, sin embargo, las raíces no dejan de existir nunca en el continuo ciclo de transformaciones. ${ }^{54}$ 'Esto basta para indicarnos que el

48 Véase n. 25.

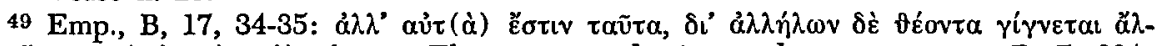

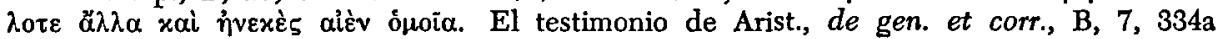
26-31, confirma la interpretación que hace Zeller, op. cit., I, 2, pág. 945 , n. 2, de la primera frase de este texto: "sie sind sie selbst, bleiben, was sie sind". Por otra parte, la

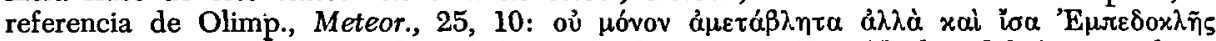

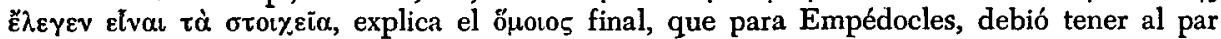
el significado de "igual" y de "semejante". Cf. Emp., B, 17, 27 y Mario Untersteiner, "Senofane e Melisso nel 'De Melisso Xenophane Gorgia" ", Antiquitas, VIII, 1-2; pág. 15 del Estratto.

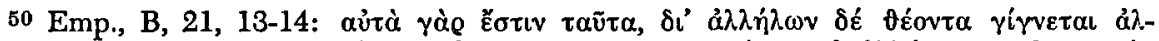

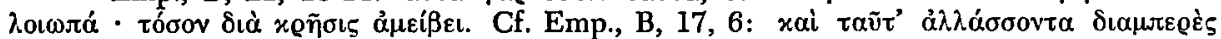

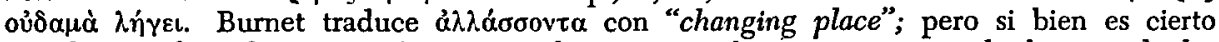
que la mezcla y la separación se cumplen gracias al trueque mutuo de lugares de las raíces (Cf. Aecio, II, 7, 6), no hay que olvidar que éstas no sólo mudan de posición, sino también de aspecto. Véase Bignone, op. cit., pág. 404 y Covotti, op. cit., págs. 168-169.

51 Emp., B, 16. Que este fragmento se refiera al Amor y el Odio lo confirma Hipol., Ref., VII, 29 (p. 211 W.).

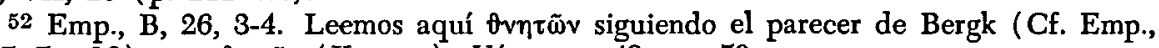
B, 37, 7 y 16) y no tnễo (Karsten). Véanse n. 49 y n. 50 .

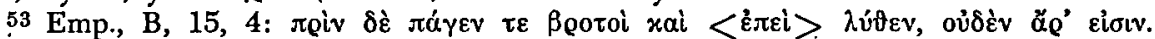
Como muy acertadamente hace observar Zeller, op. cit., 1, 2, pág. 945, n. 2, B@otoí "bezeichnet bei Emp. nicht bloss die Menschen, sondern alle vergänglichen Wesen, und ewig sind diese nur, wiefern es ihre Elemente sind".

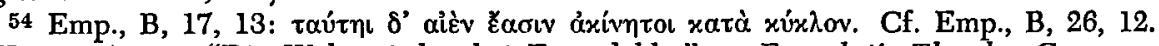
Ya H. von Arnim, "Die Weltperioden bei Empedokles" en Festschrift Theodor Gomperz, A. Hölder, Wien, 1902; pág. 18, hacía notar que, mediante áxívntot, "Empedokles nur den unerschütterten Fortbestand des Daseins betont." Recuérdese, en efecto, que áxíviros, para Parménides, designa la irrebasable alteridad de lo que existe frente al no ente absoluto. (Cf. nuestro ensayo "La noción del no ente en la filosofía de Parménides", Diánoia, I, 1955; pág. 125, n. 90.) Con esto mismo debe ponerse en conexión la frase de 
verbo Eival no se predica del mismo modo cuando se dice que algo no fue como es ahora o como será ${ }^{55}$ que cuando se dice que lo que es (iò żóv) ha sido, es y será siempre. ${ }^{50}$ En el último caso eival equivale a "existir" y en el otro, simplemente, a "ser de tal y cual otra manera". Ello se refleja en la tajante diferencia que hay entre lo que no es, tomado como lo que no existe, y lo que no es, tomado en el sentido de lo que no es como ya fue o será. Es esta diferencia, precisamente, la que hace destacar Empédocles al usar dos expresiones distintas para aludir a uno y otro tipo de no ente, recalcando más en un caso que en otro su negatividad. ${ }^{57}$ El segundo no ente es, existe; pero no el primero. De modo implícito, esto preludia ya la famosa sentencia de Tomás de Aquino: "enti et non enti aliquid secundum analogiam convenit, quia ipsum non-ens ens dicitur analogice". 58 Pero, así como en el terreno lógico no puede afirmarse que Empédocles haya caído en la cuenta de la distinción entre el ser existencial y el ser como cópula, tampoco, en el terreno metafísico, podría decirse que haya cobrado conciencia de la "analogia entis", aunque en sus fragmentos se nos haga patente el primer intento tosco de utilizarla, debido justamente a las dificultades originadas por la conjunción de la teoría eleática del ente con su propia teoría acerca de la variable condición del universo. El ser no se predicará del mismo modo en relación a lo que cae bajo el dominio de la una que en relación a lo que cae bajo el dominio de la otra.

Claro está, por otra parte, que este modo de predicar el ser ajeno al pensamiento de Parménides, no es una forma más de lo que Empédocles deno-

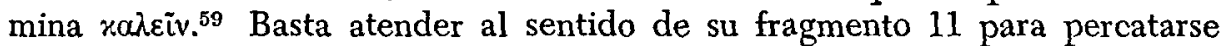
de que la expresión oử çóv no designa algo basado en una mala interpretación de los procesos cósmicos, sino algo que puede ser mal interpretado al tomársele como un absoluto no ente. Esto mismo viene a confirmárnoslo la explicación que del sentido de este modo de "ser de tal y cual otra manera" se nos hace en Emp., B, 9. La mezcla y la separación son evidentemente sus causas últimas; son lo que hace posible que algo surja a la luz, manifestándose como siendo de tal manera, o que algo desaparezca en la oscuridad al

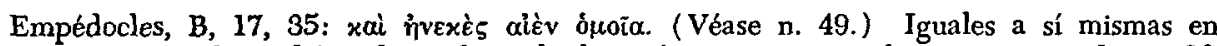
cuanto tales sólo podrían dejar de serlo las raíces si se aniquilaran por completo. $C$.

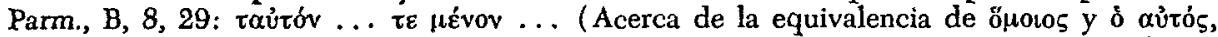
véase Raven, Pythagoreans and Eleatics, Cambridge University Press, 1948; pág. 57.) Por lo que toca al plano de la existencia, Empédocles considera, al igual que Parménides, que la principal característica de lo que existe, de las raíces, es la imposibilidad de dejar de existir, de dejar de ser igual a sí mismas, esto es, la inmutabilidad, a pesar de que en virtud de su unión en diversas proporciones varíe su aspecto. Cf. Gilbert, op. cit., págs. 106 y 109.

55 Cf. Emp., B, 21, 9.

56 Cf. Emp., B, 12.

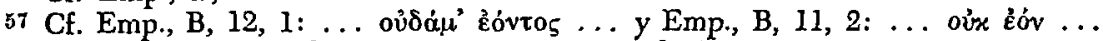

58 Tomás de Aquino, de Veritate, q. 2, a. 11, ad. 5.

59 Véase $n .43$. 
ser de otra manera. ${ }^{00}$ Dichas "presentación" y "desaparición”, a pesar de darse efectivamente y justo por ello, son, para Empédocles, lo que puede dar lugar a malas interpretaciones. ${ }^{61} \mathrm{La}$ imitación de los primeros cuatro versos de este

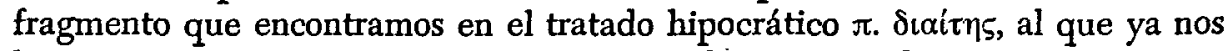
hemos referido, viene a atestiguarnos que tal es su sentido. ${ }^{62}$

De esta manera se hace el deslinde de dos órdenes. Las raíces consideradas por lo que toca únicamente a su existencia son inmutables. Cada una de ellas para dejar de ser lo que es necesitaría dejar de existir. El Fuego, por ejemplo, no puede dejar de ser Fuego a menos de no existir. Y lo mismo ocurre en relación al Amor o el Odio. Pero, por otra parte, las diversas mezclas proporcionales de raíces, las cosas, están en continua mutación; son inestables. Al mezclarse las raíces, a pesar de seguir siendo lo que son, es decir, a pesar de seguir existiendo, se enmascaran tras ese "accidente" suyo que es la cosa formada. Ya no son entonces lo que eran antes de mezclarse. No otra cosa nos quiere decir Empédocles cuando afirma que en el estado de mezcla, a diferencia de lo que ocurre en el estado de separación, las raíces "mueren unas en otras". ${ }^{63}$ Estos dos planos -la eternidad de la existencia y la mudable condición de las mezclas- explican, pues, las dos clases de no ente que encontramos en Empédocles.

Ahora bien, la cuestión del vacío surgirá precisamente en íntima conexión con esta tesis acerca de la eternidad de los seis principios. Sabemos ya que de perecer éstos enteramente no existirían más. ${ }^{64}$ En lugar de la realidad tendríamos así el no ente absoluto. Ahora bien, el sentido de este no ente es el de una carencia o falta. En efecto, si los seis principios desaparecieran no nos quedaría más que su ausencia, un desierto. ${ }^{65}$ La palabra ẹ̌quov que aquí

60 Emp., B, 9, 1 y 3-4. Tanto la mezcla como la separación pueden dar lugar a que algo surja a la luz, puesto que la separación da siempre lugar a algo nuevo que entonces se manifiesta como tal.

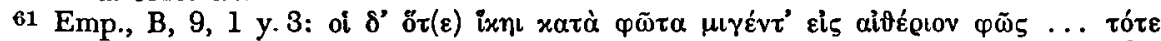

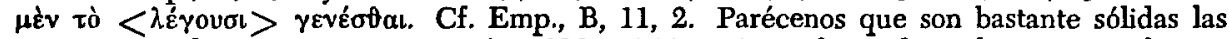
razones que da Bignone, op. cit., págs. 396 y 657, n. 1, en favor de su lectura, que hemos adoptado, del v. 1 de este fragmento. Compárese en efecto, este pasaje con la imitación

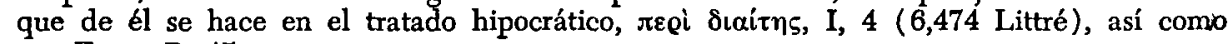
con Emp., B, 45.

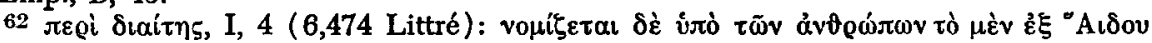

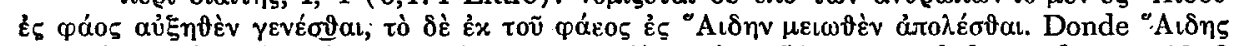

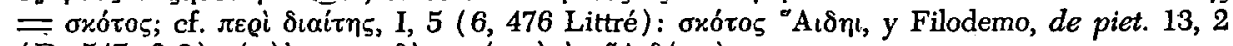

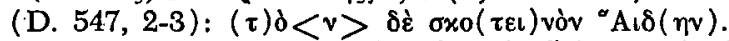

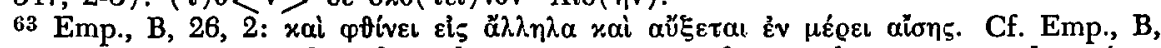
22,14 . Este verso, como lo indican los siguientes, se refiere exclusivamente a las raíces. La traducción que da el Diels-Kranz, al poner como sujeto en el verso anterior a "die Elemente und Kräfte", torna ambiguo el sentido, aunque probablemente el Amor y el Odio sean también sujetos de yoaréovor (v. 1 ).

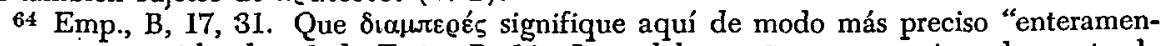
te", parece sugerirlo el v. 3 de Emp., B, 11. La palabra taṽra que se sirve de punto de referencia a los argumentos desarrollados en Emp., B, 17, 27-33, se refiere tanto a las raíces como al Amor y el Odio. Véase Bignone, op. cit., pág. 406.

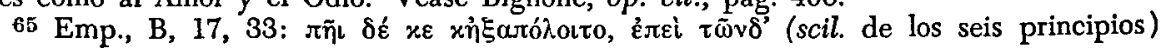


hemos intentado parafrasear con "ausencia" y "desierto" presenta indudablemente más matices que éstos; pues aunque cum gen. denota una falta o carencia, en términos generales, mienta lo desierto $\mathrm{y}$, más aún, aquello donde no se encuentra lo que ahí debía estar. ${ }^{66}$ Esto nos revela lo imposible que resulta el que algo semejante pudiera ocurrir en realidad; ya que ello equivaldría a destruir el derecho de lo que existe a estar en todo sitio y en todo tiempo. ${ }^{67}$ En consecuencia, si no hay nada donde no se encuentren las raíces y el Amor o el Odio, si no hay nada desierto, el Todo no podrá nunca incrementarse o disminuir. ¿De dónde podría venir algo más? ${ }^{68}$ Para que eso pudiera suceder se requerirían dos condiciones absurdas. Para Empédocles, tal como para Parménides, la realidad no puede sufrir un aumento a causa de que eso supondría, primero, una generación a partir del no ente absoluto ${ }^{69} \mathrm{y}$, segundo, algo exterior, vacío, donde pudiera efectuarse tal generación y darse lo generado. ${ }^{70} \mathrm{La}$ similitud de esta tesis en Empédocles y el eleata se patentiza incluso en la semejanza tan notable de las expresiones que para formularla usan el uno y el otro. ${ }^{71}$

La realidad, por ende, no tiene un "exterior" que pudiera venir a ocupar o dejar de ocupar algo más como resultado de una generación o cese. ${ }^{72} \mathbf{Y}$ justamente a este "exterior", a este desierto, es a lo que Empédocles denominará "vacío" ( $x \varepsilon v \varepsilon o ́ v)$. La identidad de éste con la carencia de realidad, con el no ente absoluto, es evidente de suyo, aunque no se la formule expresamente. Así viene a confirmarlo la contraposición que se establece en el frag. 13

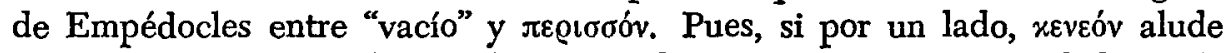

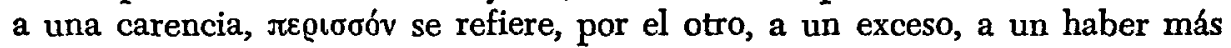
realidad de la que hay. Claro está que esto no debe entenderse como la mera negación de una condensación o rarificación; puesto que por vacío se entiende aquello donde no hay nada absolutamente. Y condensación podría haber sin que hubiera el menor aumento de realidad, entendido éste como un au-

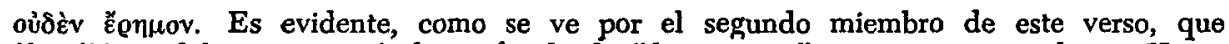

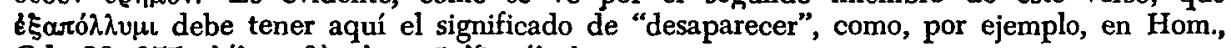

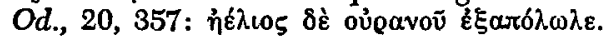

${ }_{68}$ En Aristófanes, Ach., 17-20 puede encontrarse un buen ejemplo de este último sentido.

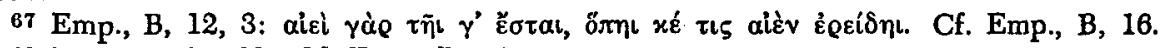

e8 Emp., B, 17, 32. Cf. Emp., B, 14.

69 Emp., B, 17, 30: rai roò

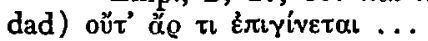

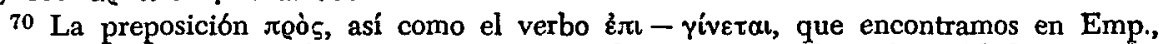
B, 17, 30, bastarían para hacer pensar en esto último. Con todo, más reveladora resulta la comparación entre Emp., B, 17, 32 y B, 14.

71 Obsérvese la correspondencia entre los verbos ésaúg $\xi \omega$ y av̌ $\xi \omega$ en Emp., B, 17, 32

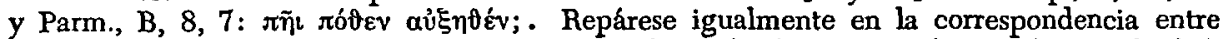

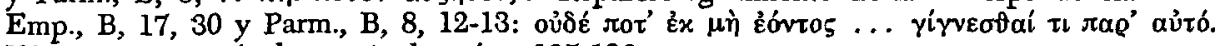
Véase nuestro artículo ya citado, págs. 125-126.

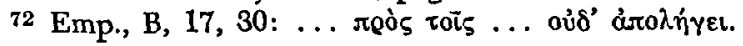


mento tanto en el "volumen", como en el número de sus ingredientes. ${ }^{73}$ En re-

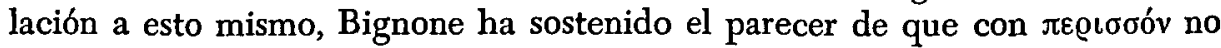
se hace más que aludir "alla perfetta sfericità dello sfero" ${ }^{74} \mathrm{Si}$ tal opinión, que, a nosotros nos parece, ha tomado demasiado en serio el testimonio del tra-

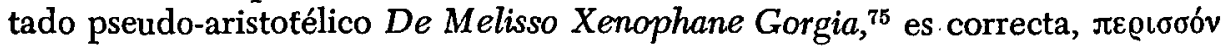
no tendría nada que ver con un aumento de la realidad; pues lo que Empédocles denomina $\Sigma$ quĩoos podría aumentar uniformemente, sin que por ello perdiera su "perfecta esfericidad". Pero es muy difícil aceptar que tal fragmento no se refiera, como el siguiente, al Todo ( $\pi \tilde{\alpha} v)$, sino a $\Sigma$ paĩoos. Por

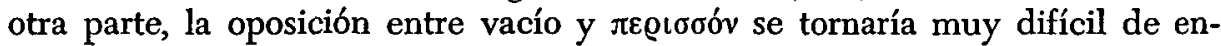
tender tomada bajo esta perspectiva.

Con lo dicho, sin embargo, no hemos hecho sino explicitar las bases de la cuestión. Ahora bien, es obvio que el vacío presenta aspectos que remiten directamente al tema de la corporalidad de las raíces y del Amor y el Odio; pues si xeveóv se identifica con la ausencia de seres corpóreos, podría de inmediato sospecharse que también se identifica con lo incorpóreo. Pero, esta interrogante nos conduce ya de modo directo a las implicaciones meramente "físicas" de la cuestión del vacío, que habrán de ayudarnos, sin duda alguna, a terminar de captar en su plenitud la esencia de los procesos del cosmos empedocliano. Por otra parte, la división que introducimos aquí, entre una "metafísica" y una "física" del vacío, no obedece a nuestro arbitrio únicamente. El experimento de la clepsidra, de que Empédocles ha dejado constancia directa en su frag. 100, permite no sólo comprender el sentido último de la teoría de los poros de Empédocles, sino también la concepción de lo corpóreo que yacía en el fondo de su pensamiento; pero, al mismo tiempo, dicha experiencia constituye, como nos decía Frenkian, "el primer ejemplo, tal vez, de un experimento científicamente desarrollado". ${ }^{76}$ Toda esta temática, en consecuencia, merece ser examinada en un sitio aparte.

Adolfo Garctía Díaz

73 Tal vez a esto último se refiere Filoponio, de gen. et corr., 11, 70 (citado por Chr. Aug. Brandis, Handbuch der Griechisch-Römischen Philosophie, G. Reimer, Berlin, 1835;

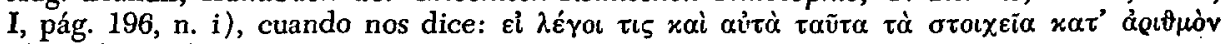

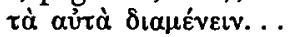

74 Bignone, op. cit., pág. 401.

75 Pseudo-Arist., de Melisso Xen. et Gorgia, 976b 25-26.

76 Aram M. Frenkian, op. cit., pág. 57. 